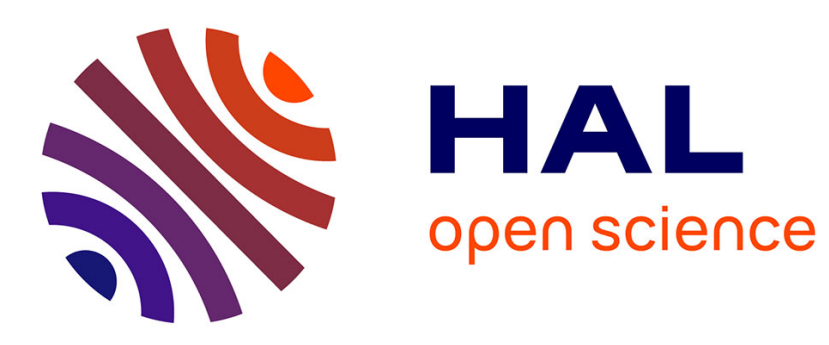

\title{
Internal structuring of silicon with multi-timescale irradiations
}

\author{
Amlan Das, Andong Wang, Olivier Utéza, David Grojo
}

\section{To cite this version:}

Amlan Das, Andong Wang, Olivier Utéza, David Grojo. Internal structuring of silicon with multitimescale irradiations. CLEO: Science and Innovations, 2021, San Jose, United States. pp.SM3B.6, 10.1364/CLEO_SI.2021.SM3B.6. hal-03383865

\section{HAL Id: hal-03383865 https://hal.science/hal-03383865}

Submitted on 18 Oct 2021

HAL is a multi-disciplinary open access archive for the deposit and dissemination of scientific research documents, whether they are published or not. The documents may come from teaching and research institutions in France or abroad, or from public or private research centers.
L'archive ouverte pluridisciplinaire $\mathbf{H A L}$, est destinée au dépôt et à la diffusion de documents scientifiques de niveau recherche, publiés ou non, émanant des établissements d'enseignement et de recherche français ou étrangers, des laboratoires publics ou privés. 


\title{
Internal structuring of silicon with multi-timescale irradiations
}

\author{
Amlan Das, Andong Wang, Olivier Utéza and David Grojo \\ Aix-Marseille Université, CNRS, LP3, F-13288 Marseille, France \\ Authorse-mail addresses: amlan.das@etu.univ-mrs.fr, david.grojo@univ-amu.fr
}

\begin{abstract}
By combining and synchronizing pulses of different durations from 170 fs to $5 \mathrm{~ns}$, we benchmark the appropriate temporal characteristics of laser pulses for 3D writing applications inside silicon. (C) 2020 The Author(s)
\end{abstract}

\section{Introduction}

Direct writing inside silicon using ultrafast infrared lasers is today attracting attention because it holds promises to create innovative microdevices with 3D architectures. However, challenges remain on finding the most appropriate experimental configurations. In the femtosecond regime, experiments show that extreme focusing conditions [1] are required for achieving modifications inside narrow gap material because a key is to circumvent detrimental propagation nonlinearities in the pre-focal region. Similarly, when longer pulses are used in the picosecond [2] or nanosecond range [3], these detrimental effects diminish gradually, leading to a situation more favorable for internal structuring. However, discrepancies persist on the most appropriate pulse duration for controllable refractive index modifications. In this work, we perform experiments with progressively stretched pulses for a rigorous study of the pulse-duration dependence. We also perform multi-pulse experiments (up to 64) combining pulses of different durations that reveal an extremely high sensitivity of the detailed temporal characteristics of irradiation. This must serve as important guidelines for laser technology developments.

\section{Results and Discussion}

In the experiments, we rely on 170 -fs pulses at $1550 \mathrm{~nm}$ with high temporal contrast as generated by optical parametric amplification. For investigations in the picosecond domain, we use a two-grating arrangement stretching the pulse. This allows to irradiate Si with pulses of different durations from 4 to $21 \mathrm{ps}$ and measure the pulse energy threshold conditions leading to permanent modifications. We also use a commercial nanosecond laser source to generate 5-ns pulses at the same wavelength of $1550 \mathrm{~nm}$ [4]. For all the available pulses, silicon sampled are irradiated with $\mathrm{NA}=0.85$ and a focus located $300 \mu \mathrm{m}$ below the surface. According to infrared microscopy observations, an energy window for confined modification is found for pulses with durations exceeding 5.4 ps. The pulse-duration dependence of this window is shown in Fig. 1(a) (green region, zone B).
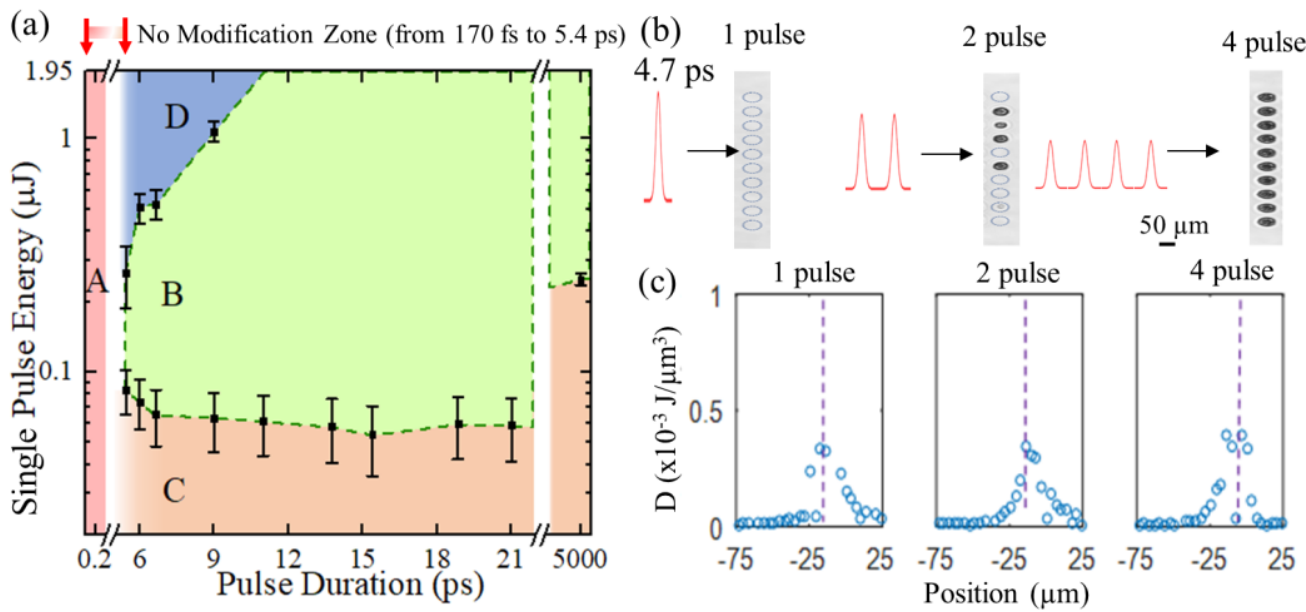

Fig. 1 (a) Observed energy windows leading to modification inside $\mathrm{Si}(\mathrm{NA}=0.85, \lambda=1.55 \mu \mathrm{m}$ ) as a function of pulse durations (green region $\mathrm{B}$ ) whereas A, C and D are non-modification region. (b) Infrared images of modifications produced with trains of 4.7-ps pulses focused (NA=0.85) at $300 \mu \mathrm{m}$ below the surface where the energy for irradiation is same $(2.1 \mu \mathrm{J} /$ train). Provided that, it is repeated 10 times for direct comparisons of damage probabilities) and (c) Absorbed energy densities along the propagation distance (geometrical focus at position=0 $\mu \mathrm{m}$ ) with trains of femtosecond pulses(up to 4 pulses) focused with $\mathrm{NA}=0.45$ 
Interestingly, we have found a dual threshold response for short picosecond pulses (5.4-11 ps) as there is an energy value threshold to exceed but also another value that should not be exceeded to achieve modification (blue region, zone D). Our measurements show that focused pulses of $4 \mathrm{ps}$ (or less) does not allow to write permanent modifications independently of the energy. This supports the idea of a peak power that should not be exceeded to avoid nonlinear delocalization of light as observed in other recent studies [2] with shorter pulses. With our longest pulse (21 ps), we find an energy threshold under $0.15 \mu \mathrm{J}$ and create repeatable micro-features depending on the applied laser energy. The repeatability indicates that the peak power is already sufficiently decreased to avoid nonlinear distortions and identifies a short-pulse limit to the large panel of applications already demonstrated in the nanosecond regime [3]. Using our pulses of $5 \mathrm{~ns}$ shows a threshold pulse energy of $\sim 0.21 \mu \mathrm{J}$ that is not significantly higher than the value found in the picosecond domain.

Supporting the idea of a minimal pulse duration required for bulk modifications, we have also investigated multipulse (or burst) approach as another way to increase the apparent pulse duration. With the help of birefringent crystals, we have generated ultrafast trains of pulses (Up to 64 pulses) to study the modification conditions [5]. Working with pulses of $4.7 \mathrm{ps}$, we show in Fig. 1(b) that increasing the number of pulses in the train improves the situation as 4 pulses lead repeatable damages inside bulk at $4.7 \mathrm{ps}$ that is inaccessible with less pulses (comparison at fixed energy). This directly supports the possibility to rely on energy density accumulation from train of low intensity ultrashort pulses to solve the limitations for bulk damage which we can see from Fig. 1(c).

Another important aspect addressed by our experiments is the strong contradictions existing among all previous works [6,7] (including ours) regarding the threshold conditions for bulk modifications in Si. This gives us a motivation to study the dependence to the temporal contrast of pulses which has been ignored so far. By combining and synchronizing our femtosecond, picosecond and nanosecond pulses we are able to simulate any contrast imperfection. The quantitative analysis of the problem reveals an extremely high sensitivity with modification ignition at intensity contrasts down to $10^{-6}$ and below. Such sensitivity has no equivalent in any other laser material processing application and cause laser-technology dependent results. This important finding allows a comprehensive reading of the literature on the topic of 3D laser writing in silicon [8].

\section{Conclusion}

In this work the basic temporal aspect of pulses is covered where we can see that the behavior of damage conditions changes drastically specifically in ps scale. Also, we have clarified some of the discrepancies observed in the previous studies to showcase an important suggestion for stable laser writing inside silicon.

\section{Acknowledgements}

This research has received funding from the European Research Council (ERC) under the European Union Horizon 2020 research and innovation program (Grant Agreement No. 724480).

\section{References}

[1] M. Chanal, V. Y. Fedorov, M. Chambonneau, R. Clady, S. Tzortzakis, and D. Grojo, "Crossing the threshold of ultrafast laser writing in bulk silicon," Nat. Commun. 8, 1-6 (2017).

[2] M. Chambonneau, L. Lavoute, D. Gaponov, V. Y. Fedorov, A. Hideur, S. Février, S. Tzortzakis, O. Utéza, and D. Grojo, " Competing nonlinear delocalization of light for laser inscription inside silicon with a 2- $\mu$ m picosecond laser," Phys. Rev. Appl. 12(2), 1 (2019).

[3] O. Tokel, A. Turnall, G. Makey, P. Elahi, T. Çolakoğlu, E. Ergeçen, Ö. Yavuz, R. Hübner, M. Zolfaghari Borra, I. Pavlov, A. Bek, R. Turan, D. K. Kesim, S. Tozburun, S. Ilday, and F. Ö. Ilday, "In-chip microstructures and photonic devices fabricated by nonlinear laser lithography deep inside silicon," Nat. Photonics 11, 639-645 (2017).

[4] A. Das, A. Wang, O. uteza and D. Grojo, "Pulse-duration dependence of laser-induced modifications inside silicon," Opt. Express 28(18), 26623-26635 (2020).

[5] A. Wang, A. Das, and D. Grojo, "Ultrafast Laser Writing Deep inside Silicon with THz-Repetition-Rate Trains of Pulses," Research 8149764, $1-11(2020)$.

[6] H. Kämmer, G. Matthäus, S. Nolte, M. Chanal, O. Utéza, and D. Grojo, "In-volume structuring of silicon using picosecond laser pulses," Appl. Phys. A Mater. Sci. Process. 124(4), 1-6 (2018).

[7] V. V. P. Sreenivas, M. Beulters, and R. B. Bergmann, "Microsized subsurface modi_cation of mono-crystalline silicon via non-linear absorption", J. Eur. Opt. Soc.-Rapid 7, 3 (2012).

[8] A. Wang, A. Das, and D. Grojo, "Temporal-contrast imperfections as drivers for ultrafast laser modifications in bulk silicon," Phys. Rev. Research 2(3), 033023 (2020). 